\title{
Recurrent Pleomorphic Adenoma of Submandibular Region
}

\author{
Aydin $\mathrm{S}^{1^{*}}$, Demir $\mathrm{MG}^{2}$, Akbulut $\mathrm{S}^{1}$, Altıntoprak $\mathrm{N}^{1}$ and Basak $\mathrm{K}^{3}$ \\ ${ }^{1}$ Dr. Lutfi Kirdar Kartal Education and Research Hospital, ENT Department, Istanbul, Turkey \\ ${ }^{2}$ Prof. Dr. Celal Ertuğ Etimesgut State Hospital ENT Department, Ankara,Turkey \\ ${ }^{3}$ Dr. Lutfi Kirdar Kartal Education and Research Hospital, Pathology Department, Istanbul, Turkey
}

*Corresponding author: Aydin S, M.D., İstasyon Caddesi Merdivenli Sokak No 5 D 6, Kartal Istanbul/TURKEY, 34860, Tel: +902164413900/1740, GSM: + 90 5327881817, Fax: +902163520083, E-mail: sedataydin63@yahoo.com

Citation: Aydın S, Demir MG, Akbulut S, Altıntoprak N, Basak K (2014) Recurrent Pleomorphic Adenoma of Submandibular Region. SAJ Cas Rep 2: 102. doi: 10.18875/2375-7043.1.302

Article history: Received: 11 November 2014, Accepted: 11 February 2015, Published: 13 February 2015

\section{Abstract}

Salivary gland tumors are the $2-3 \%$ of all tumors and great majority of cases are pleomorphic adenomas. Pleomorphic adenomas are benign tumors but rarely seen as metastatic, recurrent or malign transformating forms. Recurrent pleomorphic adenomas are seen mostly on the head and neck region. The exact cause of the pathology has not known yet but theroies are blamed. Here we represent a recurrent submandibular pleomorphic adenoma which was surigically excised by neck dissection successfully.

Keywords: Pleomorphic Adenoma; Recurrent; Metastasis, Submandibular gland

\section{Introduction}

Pleomorphic adenoma is the most common salivary gland tumor on the head and neck region [1]. Metastasizing pleomorphic adenoma is a rarely detected form of clinic antity $[2,3]$. According to the World health organisation the characteristic of this tumor is benign in histologically but distant or local metastasis are possible [3]. The cases are related with parotid gland (74\%), minor salivary gland (17\%) and submandibular gland (10\%). Also only $17 \%$ of the metastazing pleomorphic adenoma is related with previous pleomorphic adenoma. The most common site of the metastasis is detected on bone followed by head and neck region. On the head and neck area only $17 \%$ of the metastasis is seen on the regional lymph nodes.

Here we represent the metastasizing pleomorphic adeonom after a history of submandibular gland pleomorphic adenoma excision, treated with left sided neck disection successfully.

\section{Case report}

Forty five years old male patient admitted to our clinic with a previous history of left sided total submandibular gland excision due to pleomorphic adenoma in 1995. Seven years after the surgery the swelling was appeared again and the mass was resected surgically diagnosed as pleomorfic adenoma again. After the second surgery patients mass has been recurred again after a short period of time. But on the follow up in ten years time the swelling has been showed up again and spread to 1, 2 and 3 region of the left side of his neck. (Figure 1a,1b,1c,1d). Medical examination revealed left sided multiple, mass nearly $2 \mathrm{x} 3 \mathrm{~cm}$ in diameter lesions with ruberry like, well demarcated shaped on palpation filling the 1,2 and 3 region of the neck. Also patient had a left sided fascial nerve paralysis due to the first operation. According to the neck magnetic resonance examination multiple lesions which were contrast enhanced, heterogen hipointense on T1 and heterogen hyperintense on T2 weighted image with a 87x46 mm diameter in size lying on the left submandibular and surface of the sternocleidomastoid muscle (Figure 2). We performed left sided neck dissection because the tumor spread and invaded to the left 1,2 and 3 region of the neck and tumor adharent to deep neck structures and surrounding tissue. The pathlologic examination of the neck diseciton material of the 1, 2 and 3 region showed infiltrative tumoral mass with rich mixoid stroma and cells seeding to the neck smooth tissue, adipose and muscle tissues , confirm the diagnosis of pleomorphic adenoma (Figure 3a, 3b, 3c). On the 1 year follow-up there is no recurrence or complaint detected. 


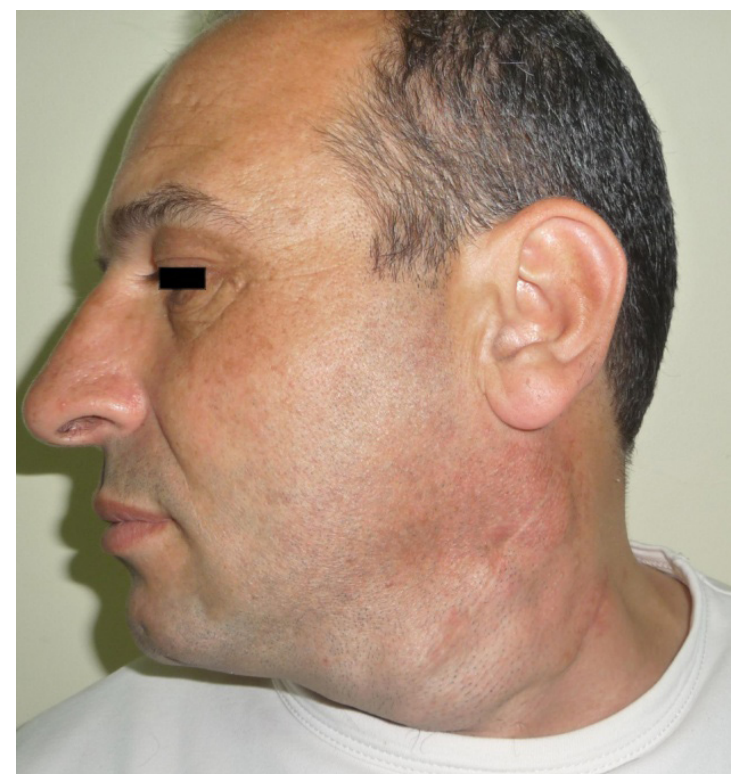

Figure 1a: The preoperative view of the mass anteriorly on the left side of the neck

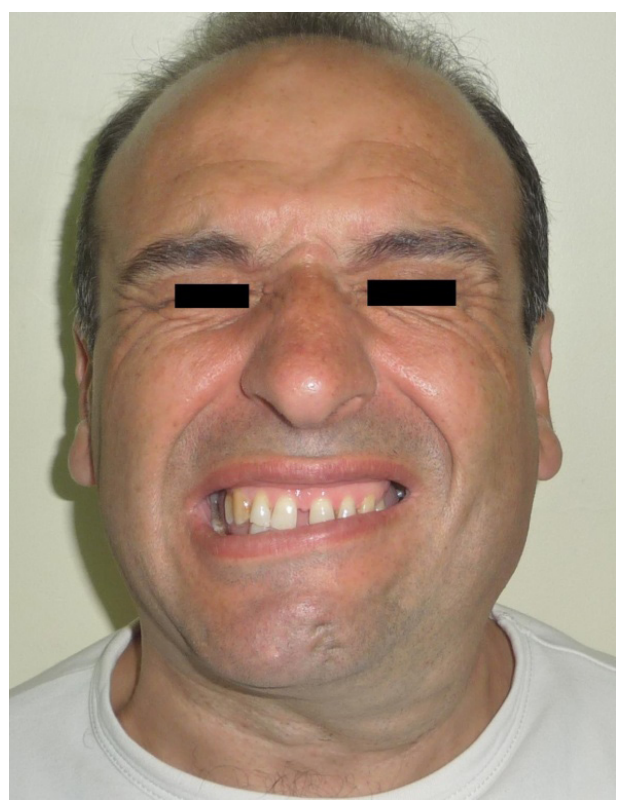

Figure 1b: The preoperative view of the mass laterally and left sided facial nerve paralyses seen of the patient

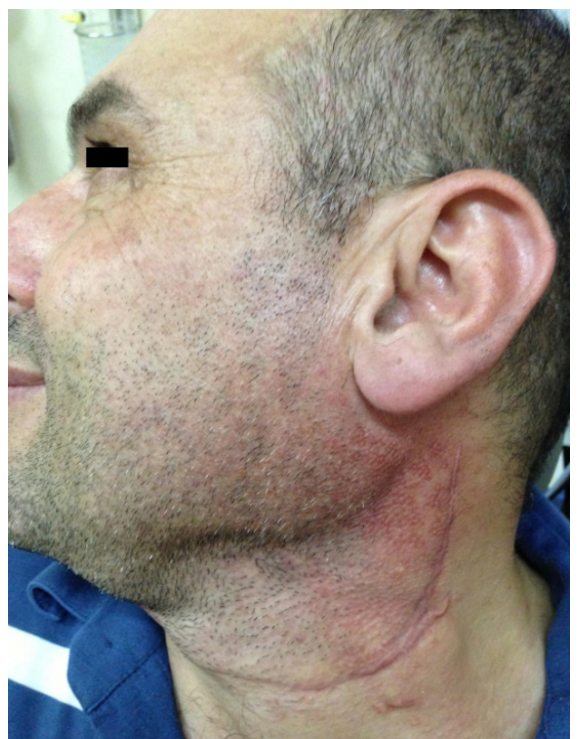

Figure 1c: Postoperative view of the patient anteriorly 


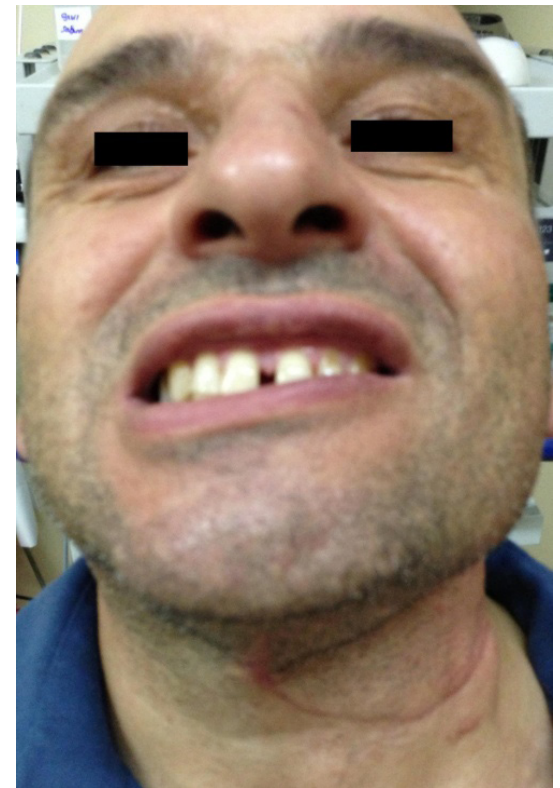

Figure 1d: Postoperative view of the patient laterally

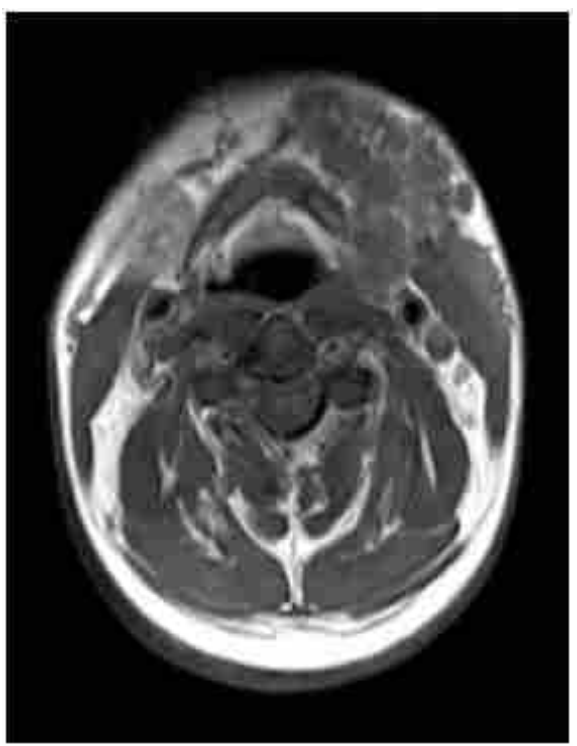

Figure 2a: Preoperative neck magnetic resonance examination multiple lesions which are contrast enhanced, heterogen hipointense on T1 weighted image with a $87 \times 46 \mathrm{~mm}$ diameter in size lying on the left submandibular and spreading the surface of the sternocleidomastoid muscle

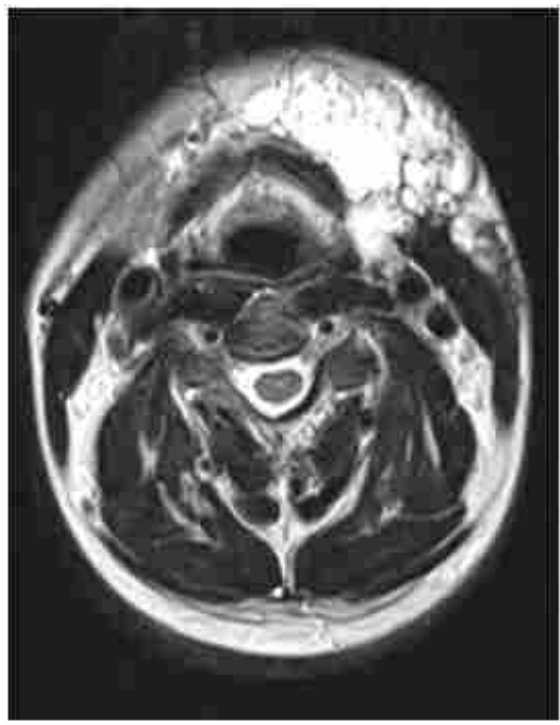

Figure 2b: Preoperative neck magnetic resonance examination multiple lesions which are contrast enhanced, heterogen hyperintense on T2 weighted image 


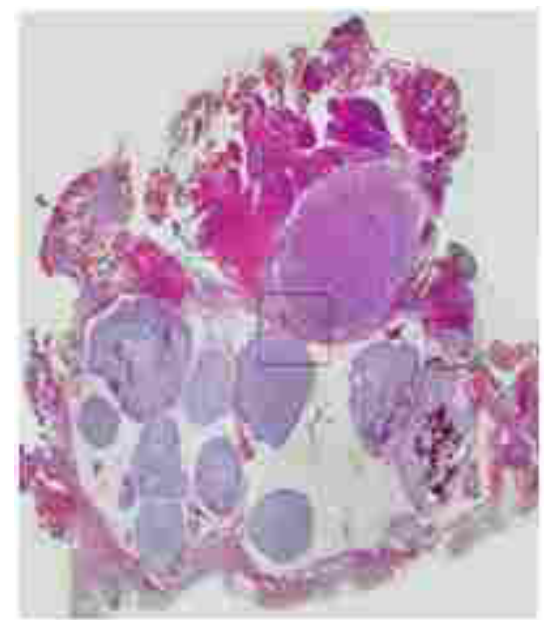

Figure 3a: Multiple tumor islands showing infiltrative development in adipose and muscle tissue with mixoid stroma (HE, x40)

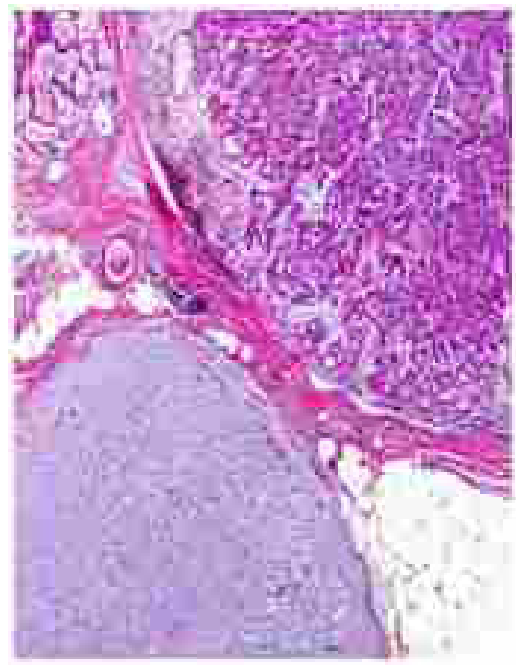

Figure 3b: Hypocelluler tumoral islands including myoepithelial cells within myxoid stroma on the left bottom of the figure and on the right upper side hypercelluler tumor islands with rich epithelial cells (HE, $\mathrm{x} 40$ )

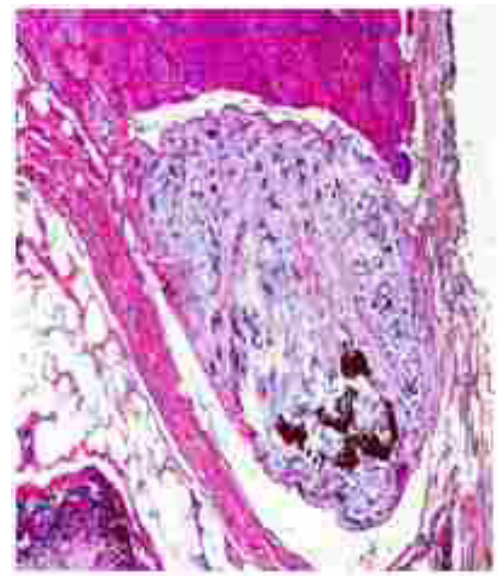

Figure 3c: Epithelial and myoepithelial tumor islands within straight muscle myxoid stroma (HE, x40)

\section{Discussion}

Salivary gland tumors correspond 1 to $4 \%$ of the all tumors. Pleomorphic adenoma is the most common form of the salivary gland tumor. Metastasizing form of the pleomorphic adenoma is really rare but mortality is extremely high when detected as $22 \%$ [2]. Generally more than $80 \%$ of cases has a history of local recurence of pleomorphic adenoma before metastatic form. Histologically metastasizing and recurrent form is not distinguishable but mainly recurrent form is detected in 5 years after surgery.

Metastatic and recurrent pleomorphic adenoma is presented mostly masses on the head and neck region and other symptoms are lower back pain, abdominal masses, cranial nerve paralyses, spinal cord compression and nasal obstruction. Our case was presented with painless, left sided multiple neck masses after 1 year from the submandibular pleomorphic adenoma excision. 
Diagnostic imaging can be done via magnetic resonance imaging (MRI) and computer tomography (CT) investigation. MRI is superior to CT image on soft tissue examination. But in general both can help us to detect the lesion. On the MRI examination multiple well demarcated mass lesion with contrast enhancement was seen on investigation. Also the image help us to distinguish the neighbourhood with the vital structures such as carotid artery and skullbase. We performed MRI image and detected the contrast enhanced mass lesion which spread all the left side of neck region.

Fine needle aspiration biopsy can be done to diagnose the tumor as in the most salivary gland tumors [5]. Excisional biopsy is not recommended due to the seeding potential of the tumor. We perform FNAB to diagnose the mass.

Local recurrence of the pleomorphic adenoma is related with enuclation of the primary tumor. This type of surgery is prone to recurrence due to the pseudopods of the pleomorhic adenoma. The recurrence rate of the primary enuclation is 20 to $45 \%$ [4]. Several theroies is blamed on the pathogenesis of the recurrent pleomorphic adenoma such as previous radiation of the tumor or surgical intervention which causes seeding and penetration to bloodsteram or lymphatics as a reason of distant metastasis. We believe that pseudopods of the tumors and seeding of the primary tumor is the potential reason of the pathology.

The treatment of pleomorphic adenoma whether primary or recurrent is essentially surgical excision [5-8]. The excision of submandibular pleomorphic adenoma is usually straight forward with little or no complications due to direct surgical access. But sometimes this excision is not sufficient.

As in our case the lesion invaded on the submandibular gland is totally resected surgically. Then recurrence occured 1 year after the sugery. We performed left sided neck disection and pathologic investigation support the reccurrent pleomorphic adenoma . Surgical excision all recurrent pleomorphic adenoma mass on the neck region with preservation of the fascial nerve is the mainstay purpose of the treatment. Recurrence can be occur on single or multiple region because of the tumor characteristics.

We emphasize the importance of total submandibular gland excision on submandibular pleomorphic adenomas and superficial paratidectomy on parotid pleomorphic adenomas to avoid recurrence and metastasis.

\section{References}

1. Alves FA, Perez DEC, Almeida OP, Lopes MA, Kowalski LP (2002) Pleomorphic adenoma of the submandibular gland: clinicopathological and immunohistochemical features of 60 cases in Brazil. Arch Otolaryngol Head Neck Surg 128: 1400-3.

2. Fernandez JR, Micas MM, Tello FJM, Berjon J, Montalvo JJ, et al. (2008) Metastatic benign pleomorphic adenoma. report of a case and review of the literature. Med Oral Patol Oral Cir Bucal 13: 193-6.

3. Nouraei SAR, Ferguson MS, Clarke PM, Sandison A, Sandhu GS, et al. (2006) Metastasizing pleomorphic salivary adenoma. Arch Otolaryngol Head Neck Surg 132: 788-93.

4. Oh YS, Eisele DW (2006) Salivary gland neoplasm: Head and Neck Surgery-Otolaryngology. (4th ed.) Lippincott Williams \&Wilkins, Philadelphia, USA.

5. Giurana RJ, Rodado C, Saez M, Bassas C (2000) Giant parotid pleomorphic adenoma involving the parapharyngeal space: report of a case. J Oral Maxillofac Surg 58: 1184-7.

6. Batsakis JG, Sneige N (1989) Pathology consultation: parapharyngeal and retropharyngeal space diseases. Ann Otol Rhinol Laryngol 98: 320-1.

7. Hugues KV III, Olsen KD, MacCafferey TV (1995) Parapharyngeal space neoplasms. Head Neck 17: 124-30.

8. Varghese BT, Sebastian P, Abraham EK, Mathews A (2003) Pleomorphic adenoma of minor salivary gland in the parapharyngeal space. World J Surg Oncol 1: 2. 